\title{
Root and canal morphology of human permanent teeth in a Sri Lankan and Japanese population
}

\author{
Roshan PEIRIS ${ }^{1 *}$ \\ ${ }^{1}$ Department of Anatomy and Physical Anthropology, Nihon University Graduate School of Dentistry at Matsudo, \\ Matsudo 271-8587, Japan
}

Received 23 July 2007; accepted 23 October 2007

\begin{abstract}
The main purpose of this study was to investigate the root and canal morphology of Sri Lankan and Japanese permanent dentition. Two thousand Sri Lankan and 976 Japanese permanent teeth were examined. The number of roots in premolars and molars and the prevalence of C-shaped (gutter shaped) roots in mandibular second molars were recorded. Root canal morphology was studied using a clearing technique. The examination of root canal systems of the teeth was based on Vertucci's classification. A higher prevalence of two-rooted maxillary first premolars was observed in Sri Lankans than in Japanese. Sri Lankan maxillary first and second premolars displayed a higher incidence of two canal and two apical foramina forms than those of Japanese. Canal morphology of mandibular first premolars showed higher occurrence of two canals with type V (1-2) canal configuration in Sri Lankans than in Japanese. In mandibular molars, Japanese presented with a higher incidence of threerooted first molars and one-rooted second molars than Sri Lankans. C-shaped root was seen in 5.7\% of Sri Lankan and $18.8 \%$ of Japanese second molars examined. In the distal root of mandibular first molars, Japanese showed a higher prevalence of two apical foramina with type IV (2) and additional canal forms than that of Sri Lankans. Japanese mandibular second molars exhibited a higher occurrence of one-root canal forms than that of Sri Lankans. In addition, mandibular incisors and canines of Sri Lankans showed a higher prevalence of two canals with type III (1-2-1) canal form than Japanese. Root and canal morphologies of Japanese and Sri Lankan people are consistent with those of people of East Asian and European (western Eurasia) origin, respectively. In human dentition, the differences of the internal canal morphology are more evident and constant than that of external root morphology among different population groups.
\end{abstract}

Key words: Root canal morphology, Permanent human dentition, Sri Lankan, Japanese, Population difference

\section{Introduction}

The study of root and canal anatomy has clinical (Vertucci, 1984; Çalişkan et al., 1995; Sert and Bayiril, 2004) and anthropological (Tratman, 1950; Dahlberg, 1965; Walker 1987, 1988a, b, c, d; Peiris et al., 2007) significance. A number of studies have shown different trends in the shape and number of roots and canals among different populations (Walker, 1987, 1988a, b, c, d; Manning, 1990a; Gulabivala et al., 2001, 2002; Sert et al., 2004). These variations appear to be genetically determined (Tratman, 1938, 1950; Sperber, 1967; Somogyi-Csimazia and Simmons, 1971; Curzon, 1974; Trope et al., 1986; Chaparro et al., 1999; Cleghorn et al., 2007) and are important in tracing the racial origins of populations.

\footnotetext{
* Correspondence to: Roshan Peiris, Department of Anatomy and Physical Anthropology, Nihon University graduate School of Dentistry at Matsudo, Sakae-cho Nishi 2-870-1, Matsudo 271-8587, Japan.

E-mail: roshan.peiris@nihon-u.ac.jp

Published online 21 February 2008

in J-STAGE (www.jstage.jst.go.jp) DOI: 10.1537/ase.070723
}

One example of such variation is the mandibular first molar with three roots. This variant has a frequency of less than $5 \%$ in people of European ancestry (British, Dutch, German, Finnish and other Europeans), and in Africans (Bushman, Bantu, Senegalese), Eurasian, and Indian populations, whereas in people with Asian traits, such as the Chinese, Eskimos and Native Americans, it occurs with a frequency of $5 \%$ to more than $40 \%$ (Somogyi-Csimazia and Simmons, 1971; Curzon, 1974; Reichart and Metah, 1981; Walker and Quackenbush, 1985; Scott and Turner, 2000). Other reported variations are single-rooted lower second molars and, more recently, C-shaped (gutter shaped) root and canal configurations. Seldom found in Caucasians, these variations have a relatively high prevalence in mandibular second molars of Chinese and other North and East Asian populations (Walker, 1988b; Weine et al., 1988; Yang et al., 1988; Manning, 1990a; Scott and Turner, 2000). In addition, mandibular premolars with Tomes' root and maxillary premolar root number also vary significantly among different populations. Tomes' root on the lower first premolar is widespread in Africans and native Australians and relatively rare in Western Eurasians (Trope et al., 1986; Scott and Turner, 2000; Lu et al., 2006; Cleghorn et al., 2007). While Sub-Saharan 
Africans show more two-rooted maxillary first premolars than any other world populations, with a frequency close to $65 \%$, people of European and Asian origin show moderately high and low frequency of occurrence, respectively (Walker, 1987; Loh, 1998; Chaparro et al., 1999; Scott and Turner, 2000).

Many investigations have examined the root canal configuration of human dentition. These studies have used a number of methods such as macroscopic sections (Barker et al., 1969), polyester resin casts (Skidmore and Bjorndal., 1971), transparencies of previously stained samples (Seeling and Gillis, 1973; Robertson et al., 1980), and radiographs of extracted teeth (Pineda and Kuttler, 1972; Sperber and Moreau, 1998). In addition, a number of studies have concluded that the root canal system varies according to race (Trope et al., 1986; Walker, 1987, 1988a, b, c, d; Manning, 1990a, b; Loh, 1998; Gulabivala et al., 2001, 2002; Sert et al., 2004; Kitabayashi, 2006; Cleghorn et al., 2007; Peiris et al., 2007). For example, Walker (1988a) reported that the occurrence of a second canal in the distal root of the mandibular first molar is very infrequent in Europeans and Africans, but more frequent in American Indians, Asians, and Aleuts and Eskimos. For the mandibular second molar, Walker (1988b) suggested that the incidence of fused roots with a lower number of identifiable canals is high in Asians and Eskimos. This finding was later supported by Manning (1990a, b) who also described a higher incidence of single-rooted mandibular second molars with $\mathrm{C}$-shaped root canals in Asians than in Europeans. Meanwhile, in a review report, Cleghorn et al. (2007) recorded a high incidence of mandibular first premolars with additional canals in Chinese, native Australians, and Sub-Saharan African populations, and a low incidence in Western Eurasian, Japanese, and American Arctic populations. Furthermore, Walker (1987) found a high frequency of single-rooted maxillary first premolars with two canals in a southern Chinese population, and emphasized that these findings are different from those of people of non-Asian origin.

The above studies have been mainly performed on single human populations. Inter-population comparisons have been made using previously reported data, it is quite possible that inter-observer error is involved. Comprehensive and systematic study of, in particular, root canal morphology of the human dentition between two or more different populations has not yet been conducted. Moreover, most of the previous research on canal morphology has been conducted on teeth of European, North American and East Asian populations. The prevalence of such morphological variations for South Asian people has rarely been reported. The only study found in the literature was that of Peiris et al. (2007), who discussed the root and canal morphology of human mandibular molars in a Sri Lankan population, and concluded that the root and canal morphology of Sri Lankan people has closer affinities with that of people of European origin. However, the information concerning the prevalence of root canal variants in the human dentition is insufficient from anthropological and clinical perspectives.

The Sri Lankan people can be briefly described as follows: the multi-ethnic population of Sri Lanka (approximately 19 million) consists of $74 \%$ Sinhalese, $18 \%$ Tamils, and $8 \%$ other minorities (Muslims, aboriginal Veddahs,
Moors, Malays, Burghers, etc.). The Sinhalese of Sri Lanka are genetically similar to the Tamils of Sri Lanka, and were always in close proximity to each other historically, linguistically, geographically and culturally (Kshatriya, 1995; Papiha et al., 1996; Peiris et al., 2006).

We conducted this study to determine the root and canal morphology of Sri Lankan and Japanese permanent dentition. We test the hypotheses that root canal morphology is different between these two populations and that the canal morphology of Sri Lankans and Japanese permanent dentition has closer affinities with that of people of European and East Asian origin, respectively. We also hypothesized that internal root canal morphology would give a clearer indication about population differences than external root morphology.

\section{Materials and Methods}

Two thousand (949 maxillary and 1051 mandibular) Sri Lankan and 976 (453 maxillary and 523 mandibular) Japanese permanent teeth (central incisor to second molar) were used in this study. Teeth were collected from cadaver specimens and from patients who came for extractions needed for several reasons such as caries, or prosthodontic or orthodontic treatments. The sex and ethnic origin of the subjects were accurately recorded. The age of the subjects at the time of tooth extraction ranged from 15 to 65 years in Sri Lankans and from 20 to 88 years in Japanese. It is acknowledged that aging, caries, tooth wear, etc., cause narrowing of the canal system due to secondary dentine deposition. However, it has been reported that they have minimal influence on the main root canal morphology (Hess, 1925). All subjects enrolled in this research responded to an informed-consent protocol, approved by the Ethics Committee of the Nihon University School of Dentistry at Matsudo and conforming to the provisions of the Declaration of Helsinki of 1995 (as revised in Edinburgh 2000).

Teeth were washed immediately after extraction and stored in $10 \%$ formalin until the collection was completed. They were then boiled in $5 \% \mathrm{NaOH}$ for $5 \mathrm{~min}$. and cleaned with $10 \% \mathrm{NaOCl}$ for $40 \mathrm{~min}$ in a super sonic cleaner to remove organic debris on the surface. Any further deposits such as calculus and bone fragments were removed by scaling and polishing. Each specimen was examined visually beneath a quartz-halogen light with the aid of a hand lens.

Recording of the number of single and multi-rooted maxillary premolars was based on Turner's five class classification (Turner, 1981) (Figure 1). A single-rooted premolar is equivalent to classes $a, b$, and c. Meanwhile, classes d and e represent two- and three-rooted premolars, respectively. Scoring of the prevalence of Tomes' root on mandibular premolars was based on the Arizona State University dental anthropology system six-grade classification (Turner et al., 1991) (Figure 2), but these grades were then combined into four categories as follows. Category 1 (grades 0-2) indicating single roots without a development groove or, if present, shallow with rounded rather than V-shaped indentation or shallow V-shaped cross section or moderately deep V-shaped cross section. Category 2 (grade 3 ): single roots with deep Vshaped development groove which extends at least one-third 

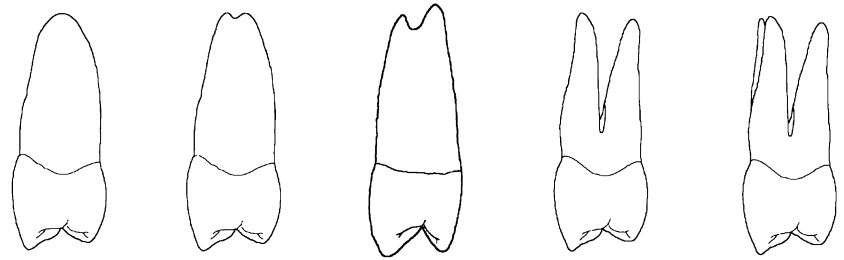

Class a
Class c
Class d nally, the teeth were rendered transparent by immersion in a solution of benzoic acid mixed with benzene and methylsalicylate for 2-3 days. At the end of this procedure, all of the samples were transparent, and there was no sign of any opacity on their surfaces.

The cleared specimens were examined under a dissecting microscope at $\times 10$ magnification and the number and type of root canals and the number of apical foramina were recorded. During the evaluation of the samples, Vertucci's classification was used as the main reference. Vertucci (1984) classified the root canal configuration of human permanent teeth into eight types (Figure 3, Figure 4a): type 1 (1), a single canal extends from the pulp chamber to the apex; type II (2-1), two separate canals leave the pulp chamber and join short of the apex to form one canal; type III (12-1), one canal leaves the pulp chamber, divides into two within the root, and then merges to exit as one canal; type IV (2), two separate and distinct canals extend from the pulp chamber to the apex; type V (1-2), one canal leaves the pulp chamber and divides short of the apex into two separate and distinct canals with separate apical foramina; type VI (2-12 ), two separate canals leave the pulp chamber, merge within the body of the root, and redivide short of the apex to exit as two distinct canals; type VII (1-2-1-2), one canal leaves the pulp chamber, divides and then rejoins within the body of the root, and finally redivides into two distinct canals short of the apex; and type VIII (3), three separate canals extend from the pulp chamber to the apex. Aberrant forms of root canals that did not fit Vertucci's classification were also evaluated.

The consistency of the observer in assessing root canal types was tested by re-examining the mesial roots of 50 randomly selected mandibular first molars $\left(\mathrm{M}_{1}\right)$ and then comparing these results to the original canal assessment. The mesial root of $M_{1}$ was selected because it showed the most

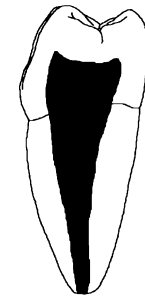

Type I

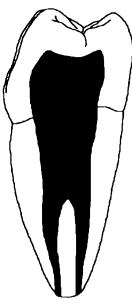

Type $\mathrm{V}$

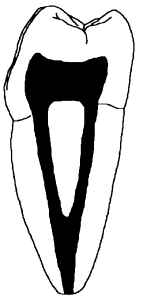

Type II

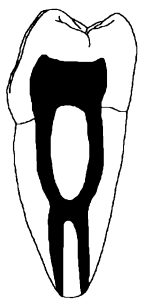

Type VI

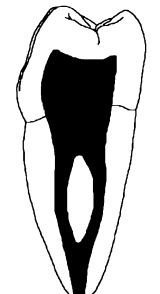

Type III

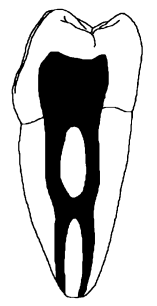

Type VII

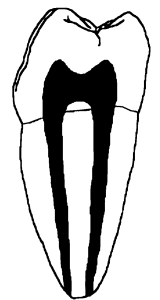

Type IV

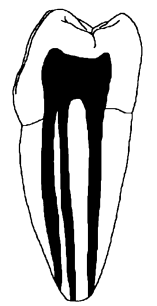

Type VIII After demineralization, the teeth were rinsed in running water for $24 \mathrm{~h}$ and then dehydrated in ascending concentrations of ethanol $(70 \%, 80 \%, 90 \%, 95 \%$, and $100 \%)$ for 5 days. Fi-

Figure 3. Vertucci's classification of root canal types (Vertucci, 1984; Peiris et al., 2007) type I, 1; type II, 2-1; type III, 1-2-1; type IV, 2; type V, 1-2; type VI, 2-1-2; type VII, 1-2-1-2; type VIII: 3. 
(A)

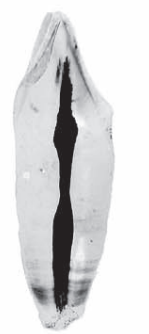

Type I

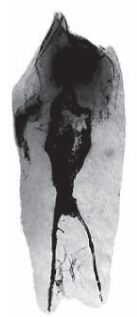

Type V

(B)

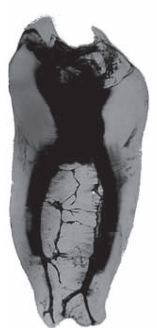

$(\operatorname{ad} 1)$

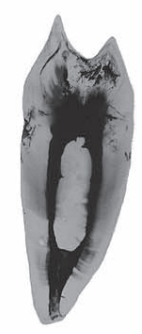

Type II

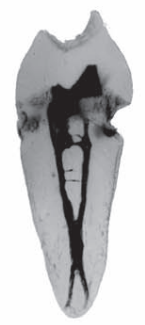

Type VI

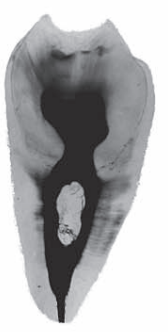

Type III

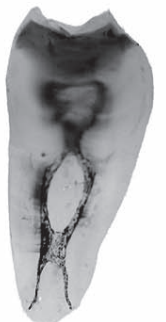

Type VII

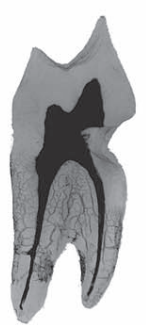

Type IV

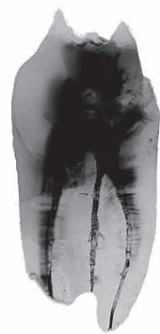

Type VIII

percentages of the root classes of premolars and the number of roots in molars are presented in Table 1-Table 4. In maxillary first premolars $\left(\mathrm{P}^{1}\right)$, while Japanese showed a higher prevalence of class $a$ and $b$ than those of Sri Lankans, class d was commonly seen in Sri Lankans (Table 1). Furthermore, two-rooted $\mathrm{P}^{1}$ was found in $32.0 \%$ of Sri Lankan teeth and in $11.1 \%$ of Japanese teeth (Fisher's exact tests, $P<0.001)$. In $\mathrm{P}^{2}$, Sri Lankans showed a higher occurrence of class $b$ than Japanese (Table 1). Meanwhile, the root morphology of maxillary molars did not show any significant difference between the two populations (Table 2). In addition, in mandibular first premolars $\left(\mathrm{P}_{1}\right)$, Sri Lankans displayed a higher frequency of category 2 than Japanese (Table 3). Tomes' root was found in $11.1 \%$ and $4.3 \%$ of the teeth studied in Sri Lankans and Japanese, respectively. However, the difference was not statistically significant. In mandibular molars, Japanese presented with a higher inci-

Table 1. Prevalence of root forms in maxillary premolars (\%)

\begin{tabular}{|c|c|c|c|c|c|c|}
\hline & \multirow{2}{*}{$n$} & \multicolumn{5}{|c|}{ Root class } \\
\hline & & $\mathrm{a}$ & $b$ & $\mathrm{c}$ & $\mathrm{d}$ & $\mathrm{e}$ \\
\hline \multicolumn{7}{|c|}{ Sri Lankan } \\
\hline $\mathrm{P}^{1 * *}$ & 153 & 36.0 & 17.7 & 14.3 & 32.0 & - \\
\hline $\mathrm{P}^{2} *$ & 114 & 85.1 & 14.1 & 0.8 & - & - \\
\hline \multicolumn{7}{|c|}{ Japanese } \\
\hline $\mathrm{P}^{1}$ & 81 & 48.1 & 28.5 & 11.1 & 11.1 & 1.2 \\
\hline $\mathrm{P}^{2}$ & 60 & 96.7 & 3.3 & - & - & - \\
\hline
\end{tabular}

Significant differences between the percentages of root classes of Sri Lankans and Japanese are denoted by asteriskes: ** $P<0.01$; * $P<0.05$ (Wilcoxon rank sum test).

(ad 3)

Table 2. Root number of maxillary molars (\%)

Figure 4. Transparent root canal appearance of permanent teeth in the present study (a) Examples for each type of Vertucci's classification (b) Additional canal configurations, commonly found: (ad 1), 2-3; (ad 2), 1-2-3; (ad 3), 3-1-2.

variable and complicated canal morphology. Concordance rate was $96 \%$, indicating that using the present classification, canal morphology could be scored with high reliability.

In the Sri Lankan sample, we combined Sri Lankan Sinhalese and Tamil data for the analysis because no statistically significant difference was observed in either root or canal morphologies between these population groups. In addition, these parameters did not significantly differ between males and females in both Sri Lankans and Japanese, and thus these groups were also combined.

JMP (version 3, SAS Institute) software was used for the statistical analysis. Wilcoxon rank sum and Fisher's exact tests were used to determine statistically significant differences. $P$ values of less than 0.05 were considered significant.

\section{Results}

\section{Root morphology}

The root morphology of maxillary premolars and mandibular molars differed between Sri Lankans and Japanese. The

\begin{tabular}{lccccc} 
& $n$ & \multicolumn{5}{c}{ No. of roots } \\
\cline { 3 - 6 } & & 1 & 2 & 3 & 4 \\
\hline Sri Lankan & & & & & \\
M $^{1}$ & 210 & - & 1.4 & 98.2 & 0.4 \\
M $^{2}$ & 213 & 14.6 & 32.9 & 52.1 & 0.4 \\
\hline Japanese & & & & & \\
M $^{1}$ & 54 & - & - & 100 & - \\
M $^{2}$ & 53 & 13.2 & 32.1 & 54.7 & - \\
\hline
\end{tabular}

The differences were not statistically significant (Wilcoxon rank sum test).

Table 3. Prevalence of root forms in mandibular premolars (\%)

\begin{tabular}{lrrrrr}
\hline & $n$ & \multicolumn{5}{c}{ Root category } \\
\cline { 3 - 6 } & & 1 & 2 & 3 & 4 \\
\hline Sri Lankan & & & & & \\
$\mathrm{P}_{1}$ & 81 & 87.7 & 8.7 & 2.4 & 1.2 \\
$\mathrm{P}_{2}$ & 191 & 96.9 & 1.0 & 1.6 & 0.5 \\
\hline Japanese & & & & & \\
$\mathrm{P}_{1}$ & 92 & 95.7 & 4.3 & - & - \\
$\mathrm{P}_{2}$ & 60 & 100 & - & - & - \\
\hline
\end{tabular}

The differences were not statistically significant (Wilcoxon rank sum test). 
Table 4. Root number of mandibular molars (\%)

\begin{tabular}{cccccc}
\hline & & \multicolumn{5}{c}{ No. of roots } \\
\cline { 3 - 6 } & & 1 & 2 & 3 & 4 \\
\hline Sri Lankan & & & & & \\
$\mathrm{M}_{1}^{* * *}$ & 295 & - & 94.4 & 5.6 & - \\
$\mathrm{M}_{2}^{* * *}$ & 312 & 10.3 & 88.3 & 1.2 & 0.2 \\
\hline Japanese & & & & & \\
$\mathrm{M}_{1}$ & 38 & - & 68.4 & 31.6 & - \\
$\mathrm{M}_{2}$ & 32 & 31.2 & 68.8 & - & - \\
\hline
\end{tabular}

Significant differences between the percentages of number of roots of Sri Lankans and Japanese are denoted by asterisks: $* * * P<0.001$ (Wilcoxon rank sum test).

dence of three-rooted $M_{1}$ and one-rooted $M_{2}$ than those of Sri Lankans (Table 4).

\section{Root canal morphology}

The percentages of root canal configurations of permanent teeth in Sri Lankans and Japanese are shown in Table 5, Table 6 . The prevalence of the number of canals and apical foramina of premolars and mandibular molars are shown in Table 7-Table 11. Different root canal morphologies between the two populations were observed in premolars among maxillary teeth and in all of the mandibular teeth ex- cept the second premolar. In maxillary teeth, $\mathrm{P}^{2}$ more commonly presented with two canals with two apical foramina of type IV, type V and type VI canal configurations in Sri Lankans than in Japanese (Table 5, Table 7). In addition, $\mathrm{P}^{1}$ exhibited higher incidence of two apical foramina in Sri Lankans than Japanese (Table 7). Meanwhile, in maxillary molars, canal morphology was not statistically significant between the two populations (Table 5, Table 8).

On the other hand, in mandibular teeth, the majority of mandibular first incisors $\left(\mathrm{I}_{1}\right)$ showed type I canal configuration in both populations. However, a higher incidence of type III canal form was seen in Sri Lankans than in Japanese (Table 6). Meanwhile, the incidence of type III canal configuration in the mandibular second incisor $\left(\mathrm{I}_{2}\right)$ was $55.0 \%$ and $30.0 \%$ in Sri Lankans and Japanese, respectively (Table 6). While in both populations, mandibular canine teeth typically presented with a single canal (type I), the presence of type III canal form was detected in $17.2 \%$ of Sri Lankan and in $4.7 \%$ of Japanese teeth (Table 6). Furthermore, in 34.6\% of Sri Lankan and $17.4 \%$ of Japanese teeth, the mandibular first premolar $\left(\mathrm{P}_{1}\right)$ was found to consist of two canals (Table 9), which corresponded mainly to the type $\mathrm{V}$ canal configuration (Table 6).

Mesial (M) root of $M_{1}$, typically presented with two canals and two apical foramina of type IV and two canals and one apical foramen of type II canal configuration in both

Table 5. Root canal morphology of the maxillary permanent teeth (\%)

\begin{tabular}{|c|c|c|c|c|c|c|c|c|c|c|}
\hline & \multirow{2}{*}{$n$} & \multicolumn{9}{|c|}{ Canal types } \\
\hline & & I & II & III & IV & V & VI & VII & VIII & A \\
\hline \multicolumn{11}{|l|}{ Sri Lankan } \\
\hline $\mathrm{I}^{1}$ & 88 & 100 & - & - & - & - & - & - & - & - \\
\hline $\mathrm{I}^{2}$ & 88 & 96.6 & - & 1.2 & - & 1.1 & - & - & - & 1.1 \\
\hline $\mathrm{C}$ & 87 & 94.2 & 2.3 & 2.3 & - & - & 1.2 & - & - & \\
\hline $\mathrm{P}^{1}$ & 153 & 1.3 & 16.3 & 2.0 & 64.0 & 5.9 & 5.9 & 0.7 & - & 3.9 \\
\hline $\mathrm{P}^{2} * * *$ & 114 & 29.8 & 19.3 & 17.5 & 10.5 & 13.2 & 7.9 & 1.8 & - & - \\
\hline \multicolumn{11}{|l|}{$\mathrm{M}^{1}$} \\
\hline$M B$ root & 206 & 26.8 & 17.6 & 3.4 & 19.0 & 16.6 & 7.3 & 5.9 & - & 3.4 \\
\hline DB root & 206 & 97.6 & - & - & - & 1.9 & - & - & - & 0.5 \\
\hline $\begin{array}{l}\text { P root } \\
\mathrm{M}^{2}\end{array}$ & 206 & 99.0 & - & - & - & 1.0 & - & - & - & - \\
\hline$M B$ root & 121 & 42.6 & 11.9 & 5.9 & 11.9 & 18.8 & 1.1 & 3.9 & - & 3.9 \\
\hline$D B$ root & 121 & 99.2 & - & - & - & 0.8 & - & - & - & - \\
\hline P root & 121 & 100 & - & - & - & - & - & - & - & - \\
\hline \multicolumn{11}{|l|}{ Japanese } \\
\hline $\mathrm{I}^{1}$ & 56 & 100 & - & - & - & - & - & - & - & - \\
\hline $\mathrm{I}^{2}$ & 66 & 94.0 & - & - & - & 4.5 & - & - & - & 1.5 \\
\hline $\mathrm{C}$ & 83 & 98.8 & - & 1.2 & - & - & - & - & - & - \\
\hline $\mathrm{P}^{1}$ & 81 & 4.9 & 29.6 & 2.5 & 45.7 & 2.5 & 8.6 & - & - & 6.2 \\
\hline $\mathrm{P}^{2}$ & 60 & 45.0 & 26.7 & 18.3 & 6.7 & - & 3.3 & - & - & - \\
\hline \multicolumn{11}{|l|}{$\mathrm{M}^{1}$} \\
\hline$M B$ root & 54 & 25.9 & 18.5 & 5.5 & 16.7 & 14.8 & 16.7 & 1.9 & - & - \\
\hline$D B$ root & 54 & 94.4 & - & - & - & 3.7 & - & 1.9 & - & - \\
\hline $\begin{array}{l}\text { Proot } \\
\mathrm{M}^{2}\end{array}$ & 54 & 98.1 & - & - & - & - & - & 1.9 & - & - \\
\hline$M B$ root & 31 & 53.6 & 7.1 & 10.7 & 17.9 & 7.1 & 3.6 & - & - & - \\
\hline DB root & 31 & 100 & - & - & - & - & - & - & - & - \\
\hline P root & 31 & 100 & - & - & - & - & - & - & - & - \\
\hline
\end{tabular}

MB, mesiobuccal; DB, distobuccal; P, palatal; A, additional canal types.

Significant differences between the percentages of canal types of Sri Lankans and Japanese are denoted by asterisks: $* * *, P<0.001$; other roots did not show any statistically significant difference (Wilcoxon rank sum test). 
Table 6. Root canal morphology of the mandibular permanent teeth (\%)

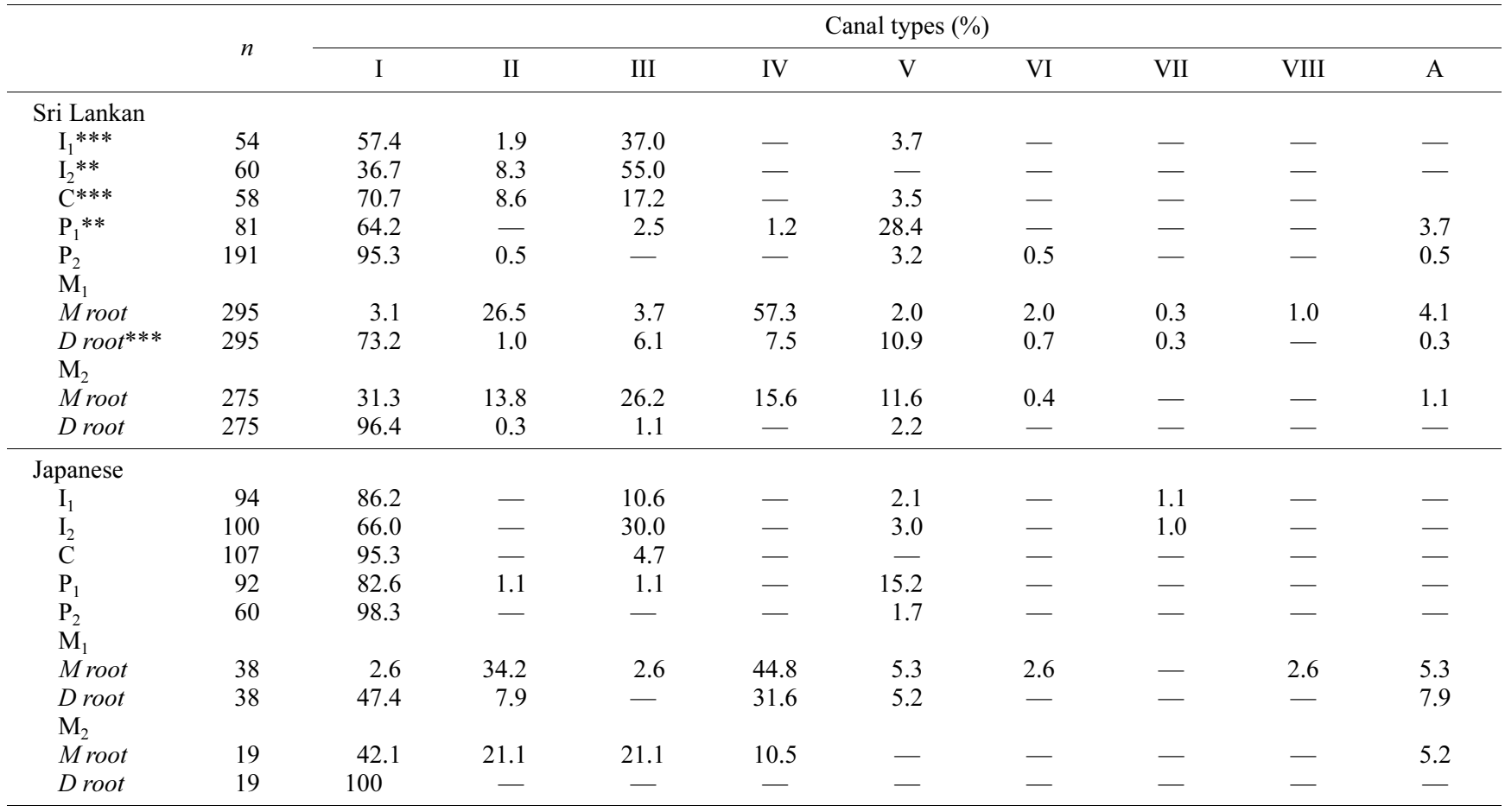

M, mesial; D, distal; A, additional canal types.

Significant differences between the percentages of canal types of Sri Lankans and Japanese are denoted by asterisks: **, $P<0.01 ; * * *$, $P<0.001$; other roots did not show any statistically significant difference (Wilcoxon rank sum test).

Table 7. Prevalence of number of apical foramina in maxillary premolars $(\%)$

\begin{tabular}{ccccc}
\hline \multirow{2}{*}{ Population } & $n$ & \multicolumn{3}{c}{ No. of apical foramina } \\
\cline { 3 - 5 } & & 1 & 2 & 3 \\
\hline Sri Lankan & & & & \\
$\mathrm{P}^{1 * *}$ & 153 & 19.6 & 79.7 & 0.7 \\
$\mathrm{P}^{2 * * *}$ & 114 & 65.8 & 34.2 & - \\
\hline Japanese & & & & \\
$\mathrm{P}^{1}$ & 81 & 37.0 & 59.3 & 3.7 \\
$\mathrm{P}^{2}$ & 60 & 90.0 & 10.0 & - \\
\hline
\end{tabular}

Significant differences between the percentages of number of apical foramina of Sri Lankans and Japanese are denoted by asterisks: **, $P<0.01 ; * * *, P<0.001$ (Wilcoxon rank sum test).

Table 8. Prevalence of number of canals in $\mathrm{M}^{2}(\%)$

\begin{tabular}{lrccccc}
\hline & & \multicolumn{5}{c}{ No. of canals } \\
\cline { 3 - 7 } & & 1 & 2 & 3 & 4 & 5 \\
\hline Sri Lankan & 213 & 1.4 & 1.9 & 49.3 & 44.1 & 3.3 \\
Japanese & 53 & - & - & 60.4 & 39.6 & - \\
\hline
\end{tabular}
test).

The difference was not statistically significant (Wilcoxon rank sum

populations (Table 6, Table 10). Furthermore, additional canal types were found in $4.1 \%$ of $\mathrm{M}_{1}$ studied in Sri Lankans and $5.3 \%$ in Japanese (Figure $4 b$ ). In Sri Lankans, most of the distal (D) roots of $M_{1}$ presented with type I (73.2\%) canal configuration. The remainder were distributed mainly between type V, type IV and type III. Meanwhile, in Japanese, there was a comparatively low prevalence of type I and a high prevalence of type IV and additional canal types (Table 6). Therefore, in the D root of $\mathrm{M}_{1}$, Japanese showed a higher incidence of two apical foramina than that of Sri Lankans (Table 10).

Of the 312 Sri Lankan $\mathrm{M}_{2}, 5.7 \%$ had single C-shaped roots. However, $\mathrm{C}$-shaped canals were found only in $1.9 \%$ of the cases. The remainder of $\mathrm{M}_{2}$ with $\mathrm{C}$-shaped roots had a total of either two or three root canals. In contrast, the prevalence of C-shaped roots and canals in Japanese were 18.8\% and $9.3 \%$, respectively. The occurrence of these two traits was significantly different between the two populations $(\mathrm{C}$ shaped roots-: Fisher's exact test, $P<0.01$; C-shaped canals-Fisher's exact test, $P<0.05$ ). In the two-rooted $\mathrm{M}_{2}$, the majority of the $M$ roots showed one or two canals with one apical foramen of type I and type III in Sri Lankans and type I, type II and type III in Japanese. In addition, the D root commonly presented with type I canal configuration (Table 6). Furthermore, Japanese $\mathrm{M}_{2}$ exhibited a higher prevalence of one-root canal and a lower prevalence of three-root canal forms than those of Sri Lankans (Table 11).

\section{Discussion}

According to Scott and Turner's classification (Scott and Turner, 2000) of human-kind, the Japanese belong to a 
Table 9. Prevalence of number of root canals in mandibular premolars $(\%)$

\begin{tabular}{lrrcc}
\hline & & \multicolumn{3}{c}{ No. of canals } \\
\cline { 3 - 5 } Population & $n$ & 1 & 2 & 3 \\
\hline Sri Lankan & & & & \\
$\mathrm{P}_{1}^{* *}$ & 81 & 64.2 & 34.6 & 1.2 \\
$\mathrm{P}_{2}$ & 191 & 95.3 & 4.7 & - \\
\hline Japanese & & & & \\
$\mathrm{P}_{1}$ & 92 & 82.6 & 17.4 & - \\
$\mathrm{P}_{2}$ & 60 & 98.3 & 1.7 & - \\
\hline
\end{tabular}

Significant difference between the percentages of number of canals of Sri Lankans and Japanese is denoted by asterisks: **, $P<0.01$ (Wilcoxon rank sum test).

Table 10. Prevalence of number of apical foramina in $\mathrm{M}_{1}(\%)$

\begin{tabular}{ccccc}
\hline & & \multicolumn{3}{c}{ No. of apical foramina } \\
\cline { 3 - 5 } & & 1 & 2 & 3 \\
\hline Sri Lankan & & & & \\
M root & 295 & 33.9 & 62.0 & 4.1 \\
D root*** & 295 & 80.4 & 19.3 & 0.3 \\
\hline Japanese & & & & \\
M root & 38 & 39.5 & 52.6 & 7.9 \\
D root & 38 & 55.3 & 36.8 & 7.9
\end{tabular}

M, mesial; D, distal. Significant differences between the percentages of number of apical foramina of Sri Lankans and Japanese are denoted by asterisks: $* * *, P<0.001$ (Wilcoxon rank sum test).

Table 11. Prevalence of number of canals in $\mathrm{M}_{2}(\%)$

\begin{tabular}{lrrrcc}
\hline & & \multicolumn{5}{c}{ No. of canals } \\
\cline { 3 - 6 } & & 1 & 2 & 3 & 4 \\
\hline Sri Lankan* & 312 & 2.8 & 32.3 & 61.7 & 3.2 \\
Japanese & 32 & 10.3 & 41.4 & 44.9 & 3.4 \\
\hline
\end{tabular}

Significant difference between the percentages of number of canals of Sri Lankans and Japanese is denoted by asterisks: ${ }^{*}, P<0.05$ (Wilcoxon rank sum test).

group of the Sino-America subdivision. They further stated that people of much of the Indian subcontinent belong to Asiatic Indian group of the Western Eurasia subdivision. In addition, Gadgil et al. (1997) reported that bulk of Indian mainland populations are Indo-European and Dravidian speakers. Meanwhile, the two main population groups of Sri Lanka, i.e. Sri Lankan Sinhalese and Tamils, are considered to have arrived in Sri Lanka, respectively, around 2500 years ago from northeastern India (presently west Bengal) and around 2100 years ago from southern India (presently Tamil Nadu). Linguistically, Sri Lankan Sinhalese are considered Aryan because their language belongs to the Indo-European family of languages and Tamils are Dravidians (Codrington, 1926). Furthermore, genetic studies show that, in general, present-day Sinhalese and Tamils of Sri Lanka are similar to other Indian populations (Saha, 1988; Kshatriya, 1995; Papiha et al., 1996). These findings imply that Sri Lankan people are genetically, culturally, and linguistically closer to the people of India, and therefore it is logical to assume that Sri Lankans too are close in ancestral terms to Europeans. This concept is further supported by recent work of Peiris et al. (2007), who investigated root and canal morphology of human mandibular molars in a Sri Lankan population.

In the present study, we confirmed that the root morphology of $\mathrm{P}^{1}, \mathrm{P}^{2}, \mathrm{M}_{1}$, and $\mathrm{M}_{2}$, and the canal morphology of $\mathrm{P}^{1}$, $\mathrm{P}^{2}$, and all of the mandibular teeth except the $\mathrm{P}_{2}$ are significantly different between Sri Lankans and Japanese. Although the root morphology of the human dentition, to a greater extent, and the canal morphology, to some extent, have been described in East Asian populations, there is little relevant evidence available in the literature for South Asian populations for direct comparison with our results. Chaparro et al. (1999) found a high incidence of two roots $(56.7 \%)$ in $\mathrm{P}^{1}$ in a southern Spanish population. In a similar study on an American Caucasian population, Carns and Skidmore (1973) repported the incidence of two roots to be $57.0 \%$. In addition, Scott and Turner (2000) recorded incidence of this trait in Western Eurasia varies from $30.0 \%$ to $60.0 \%$. With regard to the root canal morphology, Vertucci (1984) reported a high incidence $(62.0 \%)$ of type IV canal configuration in $\mathrm{P}^{1}$, with $69.0 \%$ having two apical foramina in an American Caucasian population. He further described type I canal form in $48.0 \%$ and type II in $22.0 \%$ in $\mathrm{P}^{2}$ with $75.0 \%$ and $24.0 \%$ having one and two apical foramina, respectively. In their study of a Turkish population, Sert and Bayiril (2004) reported that $62.0 \%$ of $\mathrm{P}^{1}$ had type IV canal configuration and $68.0 \%$ showed two foramina at the apex. The same report recorded type I canal form in $32.0 \%$ and type II in $20.0 \%$ in $\mathrm{P}^{2}$ with $62.0 \%$ and $36.0 \%$ having one and two apical foramina, respectively. Although our finding of tworooted $\mathrm{P}^{1}$ in Sri Lankans is lower than that of southern Spanish and American Caucasian people, it is consistent with the range of occurrence described by Scott and Turner (2000) in Western Eurasian people. Nevertheless, the results of Sri Lankan maxillary premolar canal morphology compare favorably with those of previous studies of people of European origin.

On the other hand, Walker (1987) found an incidence of $16.0 \%$ two-rooted $\mathrm{P}^{1}$ in a southern Chinese population. Aoki (1990) investigated the root morphology of maxillary premolars in a Japanese population and reported two roots in $21.5 \%$ of $\mathrm{P}^{1}$ studied. Furthermore, Tratman (1950) stated that the two-root form was distinctly uncommon in the Asian stock. Meanwhile, Walker (1987) recorded an incidence of two apical foramina in $\mathrm{P}^{1}$ in $64.0 \%$ of the cases studied in a southern Chinese population. In addition, Loh (1998) investigated root and canal anatomy of $\mathrm{P}^{1}$ in a Singaporean population, which is primarily made up of Chinese, and reported that $50.6 \%$ had two foramina at the apex. These findings are consistent with our results of Japanese, but differ from those of non-Asian origin.

Scott and Turner (2000) indicated that native Australians and Sub-Saharan African populations have the highest incidence $(>25 \%)$ of Tomes' root on the $\mathrm{P}_{1}$. The lowest incidence $(<10 \%)$ of this trait occurred in Western Eurasia, the American Arctic, and New Guinea. Furthermore, they showed this trait varies from $6.0 \%$ to $15.0 \%$ in recent Japanese. On the other hand, Vertucci (1984) and Çalişkan et al. 
(1995) found two or more root canals in $30.0 \%$ and $36.0 \%$ of $\mathrm{P}_{1}$ studied, respectively in an American Caucasian and a Turkish population. Trope et al. (1986) reported that the prevalence of more than one canal is significantly higher in American Negroids than in American Caucasians. Meanwhile, a study by Yoshioka et al. (2004) showed a relatively low occurrence of two or more canals $(19.4 \%)$ in a recent Japanese population. However, according to Walker (1988c), the incidence of this trait was $36.0 \%$ in a southern Chinese population. Our findings of root and canal morphology of Sri Lankan $P_{1}$ are consistent with those of people of European origin. Moreover, the results of the present study concerning Japanese $\mathrm{P}_{1}$ agree with the observations by Scott and Turner (2000) and Yoshioka et al. (2004) but differfrom those of Walker (1988c).

The prevalence of three roots in the Sri Lankan mandibular first molar $(5.5 \%)$ falls near the range seen for European populations $(<5 \%)$ (Scott and Turner, 2000). Peiris et al. (2007) found an incidence of three-rooted $M_{1}$ in 3\% of Sri Lankans. Our results show a higher occurrence than their figures and may be due to the large sample size used in the present study. Scott and Turner (2000) grouped North and East Asian populations into the high-frequency group $(>20 \%)$ of their basic geographic characterization of threerooted $\mathrm{M}_{1}$ frequencies. This finding is consistent with our result for the Japanese people. On the other hand, with regards to $M_{1}$ root canal morphology, Vertucci (1984) reported the prevalence of type I canals in the distal root to be $70.0 \%$, with $85.0 \%$ having one foramen at the apex in an American Caucasian population. In a Turkish population, Sert et al. (2004) encountered type I canal configurations in the distal root in $53.5 \%$ and type II and III in $12.5 \%$ and $21.0 \%$, respectively, with $87.0 \%$ having one apical foramen. Thus, in Sri Lankans, the number of apical foramina in the distal root of $\mathrm{M}_{1}(80.4 \%)$, in particular, compares favorably with those of American Caucasians and Turkish populations. Gulabivala et al. (2002), who investigated canal configurations of $\mathrm{M}_{1}$ in a Thai population, reported that $24.5 \%$ of distal root had the type IV canal form and $27.1 \%$ showed two foramina at the apex. Gulabivala et al. (2001), who performed a similar study in a Burmese population, determined the incidence of type IV canal configuration to be $18.7 \%$ and the prevalence of two apical foramina to be $25.9 \%$. Furthermore, Walker (1988a) found the incidence of two apical foramina in the distal tooth of $\mathrm{M}_{1}$ to be $28.0 \%$ in a southern Chinese population. Therefore, the high frequency of occurrence of two apical foramina $(36.8 \%)$ observed in the present study in Japanese people is in agreement with the results from East Asian populations.

C-shaped roots and root canals were first documented in 1908 (Keith, 1913) and 1911 (Keith and Knowels, 1911), after examination of the skeletal remains of members of the Neanderthal race. Later studies of root canal anatomy of $\mathrm{M}_{2}$ in Japanese (Nakayama, 1941; Kotoku, 1985), Chinese (Yang et al., 1988), and Hong Kong Chinese (Walker, $1988 \mathrm{~b}$ ) have found a high incidence of single C-shaped roots and canals. Meanwhile, among Europeans and recently in Sri Lankans, an absence (Tamse and Kaffe, 1981; Vertucci, 1984) or near absence (Weine et al., 1988; Peiris et al., 2007) of single $\mathrm{C}$-shaped roots in $\mathrm{M}_{2}$ has been described. In the present study, the prevalence of $5.7 \%$ in Sri Lankan and $18.8 \%$ in Japanese $\mathrm{M}_{2}$ is in agreement with these findings. Turning to the canal anatomy of $\mathrm{M}_{2}$, in American Caucasians (Vertucci, 1984), 65.0\% showed three canals and two canals were seen in $27.0 \%$ of the teeth examined. Furthermore, Turkish people (Sert et al., 2004) showed three canals in $63.5 \%$ of the teeth with a relatively low prevalence of two canals $(12.5 \%)$. The results of our study in Sri Lankans are in agreement with those of Vertucci (1984) but differ from those of Sert et al. (2004). This difference may be due to the different populations examined. Walker (1988b) recorded a high prevalence $(55.0 \%)$ of two canals and a low prevalence $(45.0 \%)$ of three canals in southern Chinese people. Moreover, Thai (Gulabivala et al., 2002) and Burmese (Gulabivala et al., 2001) people showed three canals in $55.0 \%$ and $42.5 \%$ of teeth, respectively. In addition, they showed forms with one root canal in $3.3 \%$ and $9.7 \%$ of the teeth, respectively. Therefore, the findings of the present study in Japanese are consistent with those from people of East Asian origin.

Interestingly, in the present investigation, we found that the root canal morphology of $\mathrm{I}_{1}, \mathrm{I}_{2}$, and mandibular canines is significantly different between Sri Lankans and Japanese. Sri Lankans $\left(\mathrm{I}_{1}, 42.6 \%, \mathrm{I}_{2}, 63.3 \%, \mathrm{C}, 29.3 \%\right)$ show two canals in these teeth more frequently than Japanese $\left(\mathrm{I}_{1}, 13.8 \%\right.$, $\mathrm{I}_{2}, 34.0 \%, \mathrm{C}, 4.7 \%$ ). Sert and Bayirli (2004) pointed out in their study of a Turkish population, that $63.5 \%$ of $\mathrm{I}_{1}$ with mainly type II $(27.0 \%)$ and type III $(26.0 \%)$ canal configurations and $61.5 \%$ of $\mathrm{I}_{2}$ with type II $(26.5 \%)$ and type III $(26.0 \%)$ canal forms, had a second canal. In addition, they detected the presence of a second canal in $25.5 \%$ of mandibular canines. Furthermore, Warren and Laws (1981) determined that $I_{1}$ and $I_{2}$ had bifid canals in $43.0 \%$ and $35.9 \%$ of teeth, respectively, in a recent New Zealand population. Vertucci (1984) has reported the incidence of two canals to be $22.0 \%$ for mandibular canines in a study on an American Caucasian population. Meanwhile, $\mathrm{I}_{1}$ and $\mathrm{I}_{2}$ have been reported to have $17.1 \%$ and $20.3 \%$ two canals, respectively in a Japanese population (Miyoshi et al., 1977). Walker (1988d) has determined this ratio to be $22.0 \%$ for $I_{1}$ and $32 \%$ for $\mathrm{I}_{2}$ in a southern Chinese population. Thus, our results concerning the root canal anatomy of Sri Lankan and Japanese $\mathrm{I}_{1}, \mathrm{I}_{2}$, and mandibular canines are in agreement with previous findings of people of European and Asian origin, respectively. It further suggests that there is a lower frequency of occurrence of mandibular incisors and canines with two canals in East Asian populations.

In the present study, it was noted that especially in the mandibular teeth, the difference of the internal canal morphology is more evident and constant than that of external root morphology between Sri Lankans and Japanese (Table 12). Thus, canal morphology seems to give a clearer indication about population differences than root morphology in the human dentition. The result that root canal anatomy is more apparently distinct between the two populations than root morphology appears to be explainable from a phylogenetic perspective of root formation. According to Carlsen (1987), the primary elements of the root complex are root cones and supernumerary radicular structures. For consistency with other publications (Turner et al., 1991, Scott and Turner, 2000), we used the term 'radical' rather than 'cone' 
Table 12. A summary of the differences of external root and internal canal morphology of maxillary and mandibular teeth between Sri Lankans and Japanese

Tooth $\begin{gathered}\text { Difference in root } \\ \text { morphology (SL vs. J) }\end{gathered} \quad \begin{gathered}\text { Difference in canal morphology } \\ \text { (SL vs. J) }\end{gathered}$

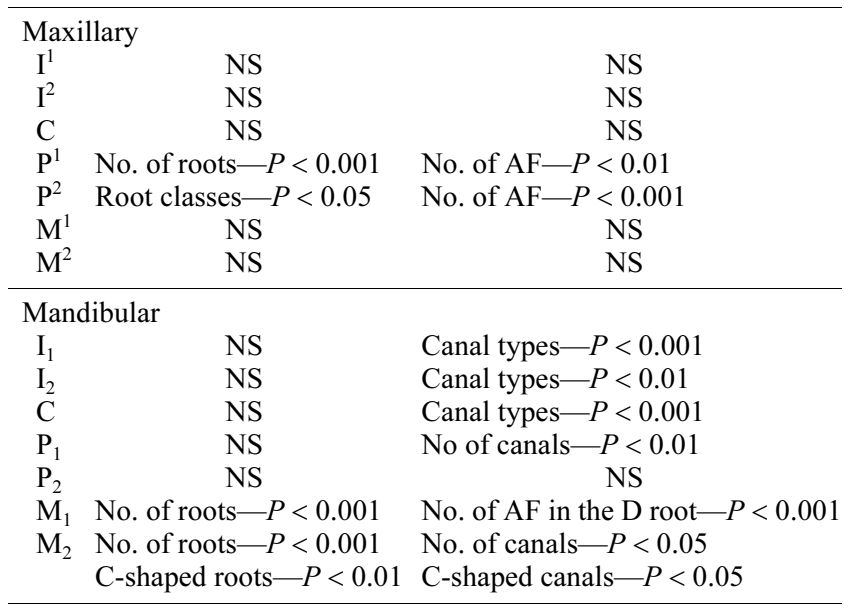

NS, Not Significant; AF, Apical Foramina; D, distal.

to refer to unseparated root-like divisions. When a root has two or more radicals, the individual root elements may be completely or incompletely divided. In completely separated roots, radicals are completely divided by an inter-radicular process at some point along the total length of a root, and the result is two or more separate roots. When radicals are incompletely divided due to only minimal penetration of the inter-radicular processes, superficial development grooves delimit the boundaries of the radicals (Carlsen, 1987). Therefore, it is possible that in an incompletely separated root, although the root is not divided externally, the root canal system is divided internally. It is evident that genes are a major controlling factor in root trait development, and in modern human populations, root (Scott and Turner, 2000) and canal (Walker, 1987, 1988a, b, c, d; Peiris et al., 2007) morphology, especially in premolars and molars, shows several consistent variants. These findings confirm the reason for different results obtained in root and canal morphology in the present study between Sri Lankans and Japanese who belong to two different subdivisions of humankind.

For example, root development of the maxillary premolars is considered because its root and canal morphology was significantly different between the two populations, with canal differences being the most evident manifestation of this variation (Table 12). Maxillary premolar roots are made up of two or three radicals. When only development grooves delimit the radical boundaries, these are single rooted. When the radicals are bifurcated, these teeth may have two or three roots. Depending on the degree of development or penetration of the inter-radicular processes, Carlsen (1987) described six variants of root and canal morphologies in human maxillary premolars (Figure 5). In $\mathrm{P}^{1}$ and $\mathrm{P}^{2}$, respectively, two- or one-rooted variants with two main canals at the apex and one-rooted variants with one main canal at the

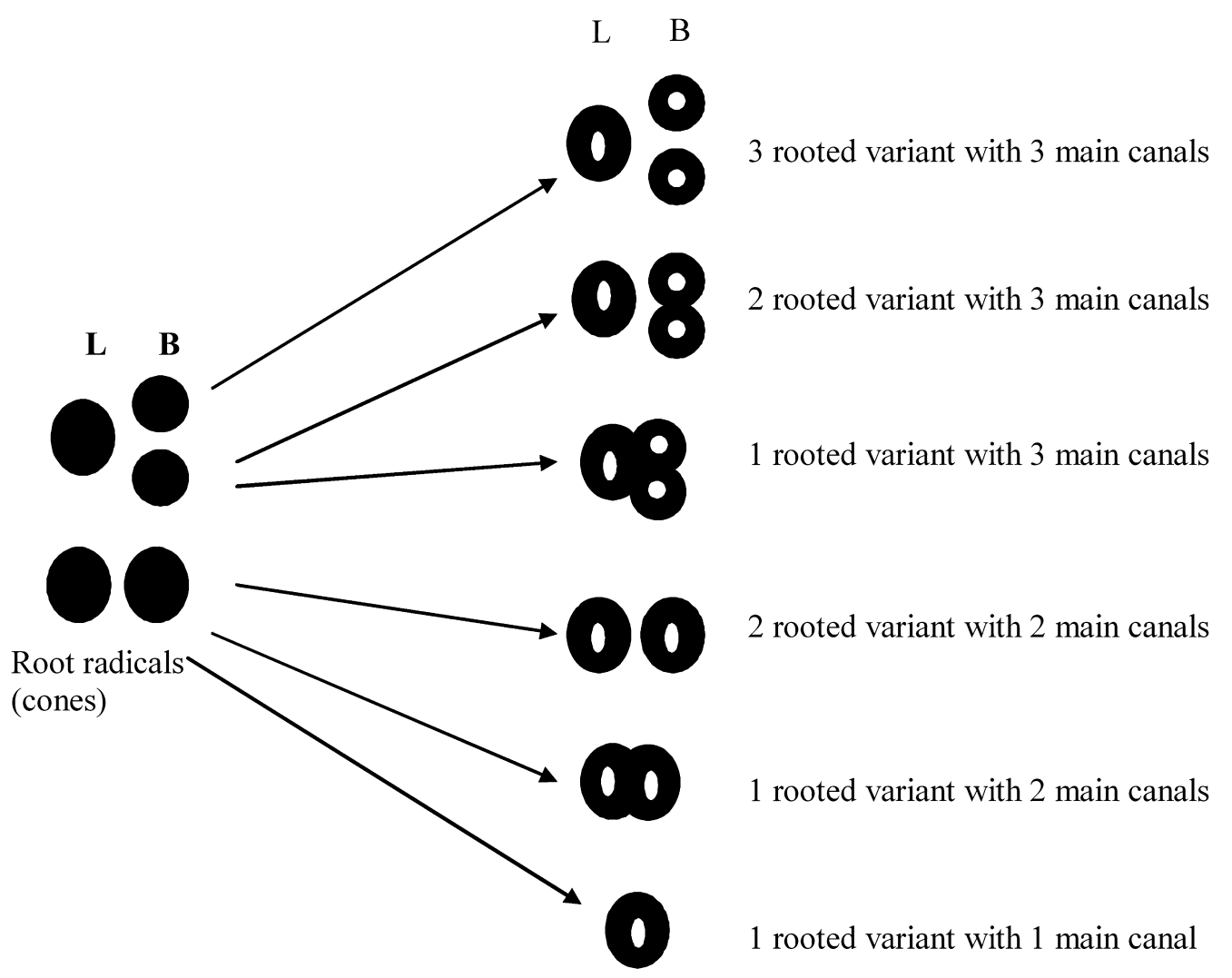

Figure 5. Diagrammatic representation of the root and canal variants of maxillary premolars (modified from Carlsen, 1987) L, lingual; B, buccal 
apex occur most frequently. Furthermore, one- and tworooted maxillary premolars show three and two variable canal morphologies, respectively (Figure 5). This seems to be the probable reason for the highly significant canal morphology shown between Sri Lankans and Japanese, especially in $\mathrm{P}^{2}$, which is commonly one-rooted.

\section{Conclusions}

The present investigation showed that the permanent maxillary and mandibular root and canal morphology of Japanese is consistent with that of people of East Asian origin. It further confirmed that root and canal morphology of Sri Lankans has closer affinities with that of people of European than of East Asian origin and supports the hypothesis that Sri Lankans exhibit closer ties to people of European origin (Western Eurasia). In addition, the present study further reinforces the concept that root canal morphology is variable among different population groups. Furthermore, we demonstrated that the difference of the internal canal morphology is more evident and constant than that of external root morphology among different populations. Therefore, canal morphology seems to give a clearer indication about population differences than root morphology in the human dentition. It is important to be familiar with these variations because ultimately they may have both clinical and anthropological significance. To date, comparatively few studies that discuss root canal morphology in different world populations are available in the literature. In order to carry out a more comprehensive discussion of interpopulation differences and the evolutionary pattern of human root and canal morphology, further studies need to be executed in various racial groups from both modern and historic/prehistoric contexts.

\section{Acknowledgments}

The author expresses his gratitude to Professor Eisaku Kanazawa (Department of Anatomy and Physical Anthropology, Nihon University Graduate School of Dentistry at Matsudo, Japan) for his instructions and guidance throughout. The author is also grateful to Professor Shin Aizawa (Nihon University School of Medicine), Professor Kenjiro Matsuno (Dokkyo University School of Medicine), Professor Ikuo Kageyama (Nihon Dental University School of Dentistry at Niigata), Dr. T.N. Pitakotuwage, Dr. D. Adikari, Dr. S.P.K. Herath, and Dr. N. Pathirana for their support. The author thanks Dr. Kayoko Sasaki, Dr. Masami Takahashi, and all members of the Department of Anatomy and Physical Anthropology, Nihon University School of Dentistry at Matsudo for their kind cooperation in carrying out this work.

\section{References}

Aoki K. (1990) Morphological studies on the roots of maxillary premolars in Japanese. Shikwa Gakuho, 90: 181-199 (in Japanese).

Barker B.C.W., Lockett B.C., and Parsons K.C. (1969) The demonstration of root canal anatomy. Australian Dental Journal, 14: $37-41$
Cališkan M.K., Pehlivan Y., Sepetçioğlu F., Türkün M., and Tuncer S.S. (1995) Root canal morphology of human permanent teeth in a Turkish population. Journal of Endodontics, 21: 200-204.

Carlsen O. (1987) Dental Morphology: Classification. Copenhagen, Munksgaard, pp. 83-95.

Carns E.J. and Skidmore A.E. (1973) Configurations and deviations of root canals of maxillary first premolars. Oral Surgery, Oral Medicinem Oral Pathology, 36: 880-886.

Chaparro A.J., Segura J.J., Guerrero E., Jimenez-Rubio A., Murillo C., and Feito J.J. (1999) Number of roots and canals in maxillary first premolars: study of an Andalusian population. Endodontics and Dental Traumatology, 15: 65-67.

Cleghorn B.M., Christie W.H., and Dong C.C. (2007) The root and canal morphology of the human mandibular first premolar: a literature review. Journal of Endodontics, 33: 509-516.

Codrington H.W. (1926) A short history of Sri Lanka, Vol. 1: Classification. Macmillan, London, pp. 1-11.

Curzon M.E.J. (1974) Miscegenation and the prevalence of threerooted mandibular first molars in the Baffin Eskimo. Community Dentistry and Oral Epidemiology, 2: 130-131.

Dahlberg A.A. (1965) Geological distribution and origin of dentition. International Dental Journal, 15: 348-355.

Gadgil M., Joshi N.V., Shambu Prasad U.V., Manoharan S., and Suresh P. (1997) Peopling of India. In: Balasubramanian D. and Appaji Rao N. (eds.), The Indian human heritage. University Press, Hyderabad, pp. 100-129.

Gulabivala K., Aung T.H., Alavi A., and Ng Y.L. (2001) Root and canal morphology of Burmese mandibular molars. International Endodontic Journal, 34: 359-370.

Gulabivala K., Opasanon A., Ng Y.L., and Alavi A. (2002) Root and canal morphology of Thai mandibular molars. International Endodontic Journal, 35: 56-62.

Hess W. (1925) The anatomy of the root canals of the teeth of the permanent dentition: Classification. John Bale, Sons and Danielsson Ltd., London, pp. 4-49.

Keith A. and Knowels F.H.S. (1911) The description of teeth of Paleolithic man from Jercy. Journal of Anatomy and Physiology, 46: 12-27.

Keith A. (1913) Problems relating to the teeth of earlier forms of prehistoric man. Proceedings of the Royal Society of Medicine (Odontology section), 6: 103-124.

Kitabayashi C. (2006) Dental morphology of the mandibular first molar in modern Japanese population according to number of root canals - comparison of groups with three and four root canals. The Aichi-Gakuin Journal of Dental Science, 44: 1527.

Kotoku K. (1985) Morphological studies on the roots of the Japanese mandibular second molars. Shikwa Gakuho, 85: 43-64 (in Japanese).

Kshatriya G.K. (1995) Genetic affinities of Sri Lankan populations. Human Biology, 67: 843-866.

Loh H.S. (1998) Root morphology of the maxillary first premolar in Singaporeans. Australian Dental Journal, 43: 399-402.

Lu T.Y., Yang S.F., and Pai S.F. (2006) Complicated root canal morphology of mandibular first premolar in a Chinese population using the cross section method. Journal of Endodontics, 32: $932-936$.

Manning S.A. (1990a) Root canal anatomy of mandibular second molars. Part I. International Endodontic Journal, 23: 34-39.

Manning S.A. (1990b) Root canal anatomy of mandibular second molars. Part II C-shaped canals. International Endodontic Journal, 23: 40-45.

Miyoshi S., Fujiwara J., Tsuji Y., Nakata T., and Yamamoto K. (1977) Bifurcated root canals and crown diameter. Journal of Dental Research, 56: 1425.

Nakayama A. (1941) Gutter-shaped root in human mandibular molars. Kokubyo Zasshi, 15: 275-281 (in Japanese).

Papiha S.S., Mastana S.S., and Jayasekara R. (1996) Genetic variation in Sri Lanka. Human Biology, 68: 707-737. 
Peiris R., Nanayakkara D., and Kageyama I. (2006) Crown dimensions of the mandibular molars in two ethnic groups in Sri Lanka. Anthropological Science, 114: 89-92.

Peiris R., Takahashi M., Sasaki K., and Kanazawa E. (2007) Root and canal morphology of permanent mandibular molars in a Sri Lankan population. Odontology, 95: 16-23.

Pineda F. and Kuttler Y. (1972) Mesiodistal and buccolingual roentgenographic investigation of 7275 root canals. Oral Surgery, Oral Medicine, Oral Pathology, 33: 101-110.

Reichart P.A. and Metah D. (1981) Three-rooted permanent mandibular first molars in the Thai. Community Dentistry and Oral Epidemiology, 9: 191-192.

Robertson D., Leeb I.J., Mckee M., and Brewer E. (1980) A clearing technique for the study of root canal systems. Journal of Endodontics, 8: 421-424.

Saha N. (1988) Blood genetic markers in Sri Lankan populationsreappraisal of the legend of Prince Vijaya. American Journal of Physical Anthropology, 76: 217-225.

Scott G.R. and Turner C.G. II (2000) The anthropology of modern human teeth: Classification. Cambridge University press, Cambridge.

Seeling A. and Gillis R. (1973) Preparation of cleared specimens for pulp cavity studies. Journal of Dental Research, 52: 1154.

Sert S., Aslanalp V., and Tanalp J. (2004) Investigation of the root canal configurations of mandibular permanent teeth in the Turkish population. International Endodontic Journal, 37: 494-499.

Sert S. and Bayiril G.S. (2004) Evaluation of the root canal configuration of the mandibular and maxillary permanent teeth by gender in the Turkish population. Journal of Endodontics, 30: 391-398.

Skidmore A.E. and Bjorndal A.M. (1971) Root canal morphology of the human mandibular first molar. Oral Surgery Oral Medicine Oral Pathology, 32: 778-784.

Somogyi-Csimazia W. and Simmons A.J. (1971) Three-rooted mandibular first molars in Alberta Indian Children. Journal of Canadian Dental Association, 37: 105-106.

Sperber G.H. (1967) Genetic mechanisms and anomalies in odontogenesis. Journal of Canadian Dental Association, 33: 433442

Sperber G.H. and Moreau J.L. (1998) Study of the number of roots and canals in Senegalese first permanent mandibular molars. International Endodontic Journal, 31: 117-122.

Tamse A. and Kaffe I. (1981) Radiographic survey of the prevalence of conical lower second molars. International Endodontic Journal, 14: 188-190.

Tratman E.K. (1938) Three-rooted lower molars in man and their racial distribution. British Dental Journal, 64: 264-274.

Tratman E.K. (1950) A comparison of the teeth of people IndoEuropean racial stock with Mongoloid racial stock. Dental Record, 70: 31-53.
Trope M., Elfenbein L., and Tronstad L. (1986) Mandibular premolars with more than one root canal in different race groups. Journal of Endodontics, 12(8): 343-345.

Turner C.G. II (1981) Root number determination in maxillary first premolar for modern human populations. American Journal of Physical Anthropology, 54: 59-62.

Turner C.G. II, Nichol C.R., and Scott G.R. (1991) Scoring procedures for key morphological Traits of the permanent dentition: The Arizona State University dental anthropology system. In: Kelley M.A. and Larson C.S. (eds), Advances in Dental Anthropology. Wiley-Liss, New York, pp. 13-31.

Vertucci F.J. (1984) Root canal anatomy of the human permanent teeth. Oral Surgery, Oral Medicine, Oral Pathology, 58: 589599.

Walker R.T. and Quackenbush L.E. (1985) Three-rooted lower first permanent molars in Hong Kong Chinese. British Dental Journal, 159: 298-299.

Walker R.T. (1987) Root form and canal anatomy of maxillary first premolars in a southern Chinese population. Endodontics and Dental Traumatology, 3: 130-134.

Walker R.T. (1988a) Root form and canal anatomy of mandibular first molars in a Southern Chinese population. Endodontics and Dental Traumatology, 4: 19-21.

Walker R.T. (1988b) Root form and canal anatomy of mandibular second molars in a Southern Chinese population. Journal of Endodontics, 14: 325-329

Walker R.T. (1988c) Root canal anatomy of mandibular first premolars in a southern Chinese population. Endodontics and Dental Traumatology, 4: 226-228.

Walker R.T. (1988d) The root canal anatomy of mandibular incisors in a southern Chinese population. International Endodontic Journal, 21: 218-223.

Warren E.M. and Laws A.J. (1981) The relationship between crown size and the incidence of bifid root canals in mandibular incisor teeth. Oral Surgery Oral Medicine Oral Pathology, 52: 425-429.

Weine F.S., Pasiewicz R.A., and Rice R.T. (1988) Canal configuration of the mandibular second molar using a clinically oriented in vitro method. Journal of Endodontics, 14: 207-213.

Yang Z.P., Yang S.F., Lin Y.C., Shay J.C., and Chi C.Y. (1988) Cshaped root canals in mandibular second molars in a Chinese population. Endodontics and Dental Traumatology, 4: 160163.

Yoshioka T., Villegas J.C., Kobayashi C., and Suda H. (2004) Radiographic evaluation of root canal multiplicity in mandibular first premolars. Journal of Endodontics, 30: 73-74.

Yoshiuchi Y., Takahashi K., and Yokochi C. (1972) Studies on the anatomical forms of the pulp cavities with new method of vacuum injection (II) - Accessory canal and apical ramification. Japanese Journal Oral Biology, 14: 156-185 (in Japanese). 